\title{
The effect of psycho-educational intervention on improving ego imparement, human representation and indicators in patients with bipolar disorder
}

\author{
Negin Anbari Meybodi ${ }^{1}$, Sajjad Basharpoor ${ }^{2}$, Seifollah Aghajani ${ }^{3}$, Elham Bina $^{4}$ \\ 1-Phd student in psychology, Faculty of Psychology and Educational Sciences, Mohaghegh Ardabili University, \\ Ardabil, Iran (Corresponding Author). $\quad$ E-mail: Negin.Anbari@gmail.com \\ 2- Associate professor of General psychology, Faculty of Psychology and Educational Sciences, Mohaghegh \\ Ardabili University, Ardabil, Iran. \\ 3- Associate professor of General psychology, Faculty of Psychology and Educational Sciences, Mohaghegh \\ Ardabili University, Ardabil, Iran. \\ 4- M.Sc. in clinical psychology, Faculty of Psychology and Educational Sciences, Azad Islamic University of \\ Semnan, Semnan, Iran.
}

Received: 23/08/2019 Accepted: 10/11/2019

\begin{abstract}
Introduction: Bipolar disorder is one of the most problematic disorders around the world. According to the long course and the tendency to relapse into this disease, effective psychological interventions are important.

Aim: The present study was carried out with the aim of investigating the effectiveness of psycho-educational intervention on improving Ego impairment, human representation, and special indices in patients with bipolar disorder.
\end{abstract}

Method: In this quasi-experimental tow-group study (experimentation and control group), with measurements in pre-test, post-test and follow-up, 30 bipolar patients were selected from patients with bipolar disorder that were hospitalized in the present or past in the Kowsar psychiatric hospital in Semnan. They were randomly assigned to experimental group $(n=15)$ and control group $(\mathrm{N}=15)$. Improvement of Ego impairement, poor human representation, good human representation and special indices were tested in every five stages of the pre-test, post-test and 3 follow - up phases by Rorschach test. Then the data were analyzed using repeated measures designs.

Results: The findings indicated that Barcelona psycho-educational intervention is effective in improving Ego impairment, object relationships and thought process in patients with bipolar disorder. In addition, in reducing the effectiveness of this intervention method, the time factor is not affected $(\mathrm{p}<0.05)$.

Conclusion: The Barcelona psycho-educational intervention caused to improving Ego impairment, object relationships and thought process in patients with bipolar disorder.

Keywords: Psycho-educational intervention, Ego imparement, Good human representation, Poor human representation, Special indicators, Bipolar disorder 


\title{
اثر بخشى مداخله روانى - آموزشى بر بهبود آسيب ايكو، بازنمايى هاى انسانى

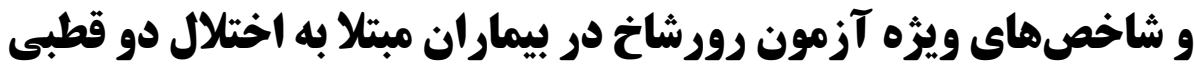

\author{
نكين انبارى ميبدى'، سجاد بشر يور '، سيف الله آقاجانى"، الهام بينا \\ ا.دانشجو دكترى روانشناسى، دانشكده علوم تربيتى و روانشناسى، دانشكاه محقق اردبيلى، اردبيل، ايران (مولف مسئول).
} ايميل: Negin.Anbari@gmail.com r. دانشيار گروه آموزشى روانشناسى، دانشكده روانشناسى و علوم تربيتى، دانشكاه محقق اردبيلى، اردبيل، ايران.

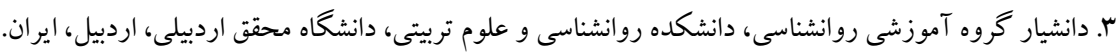

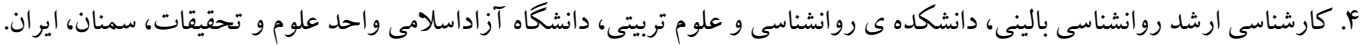

مقدمه: اختلال دوقطبى، يكى از ناتوان كنندهترين اختلالات در سراسر دنياست. با توجه به سير طولانى و تمايل به عود اين بيمارى مداخلات روانشناختى مؤثر اهميت يِيدا مى كند.

هدف: مطالعهى حاضر با هدف بررسى اثربخشى مداخله روانى - آموزشى بر بهبود آسيب ايخو، بازنمايى هاى انسانى و شاخص هاى ويزٔه در بيماران مبتلا به اختلال دو قطبى انجام شد.

روش: در اين مطالعه شبه آزمايشى دو گروهى (گروه آزمايش و كنترل)، با سنجش در بيش آزمون، بس آزمون و بيخيرى، ·ـ

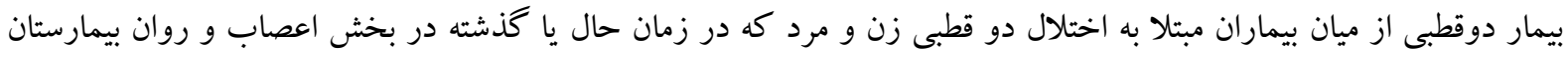

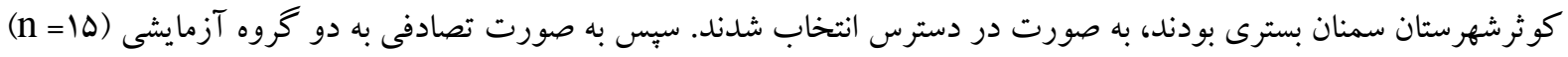

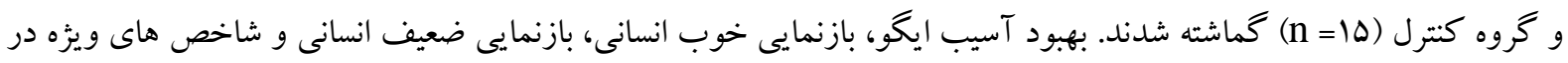

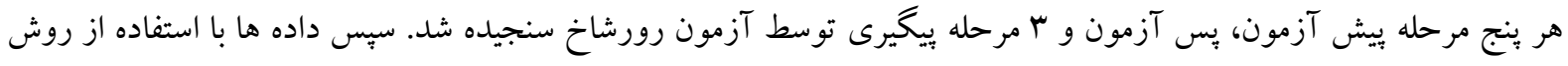
تحليل اندازه گيرى هاى مكرر تحليل شدند. يافته ها: يافته ها نشان داد مداخله ى روانى - آموزشى گروهى بارسلونا در بهبود آسيب ايخو، روابط ابثه و يردازش فكر، در

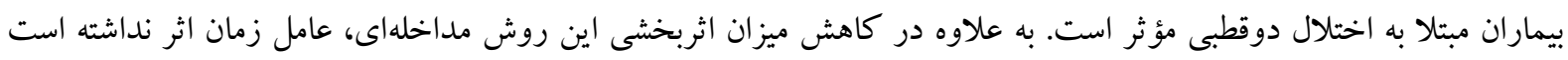

نتيجه كيرى: مداخله ى روانى - آموزشى گروهى بارسلونا باعث بهبود آسيب ايخو، روابط ابزه و بردازش فكر، در بيماران دوقطبى مى شود.

كليد وازهها: مداخله روانى - آموزشى، آسيب ايخو، بازنمايى انسانى خوب، بازنمايى انسانى ضعيف، شاخصهاى ويزه، اختلال

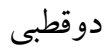


شناختى (تيسيا و فونتو لاكيس '، ها ·Y) و احتمال بروز مقدمه

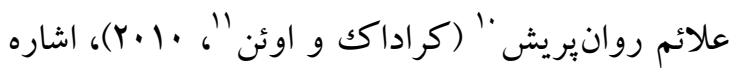
كرد. يكى از علائم اختلال دوقطبى كه در بعضى از اين

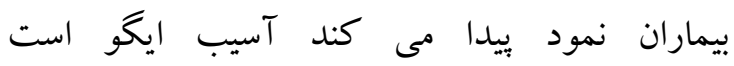

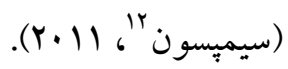

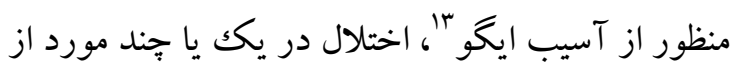

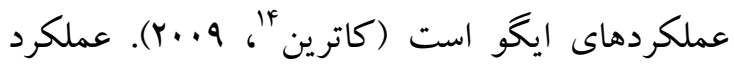

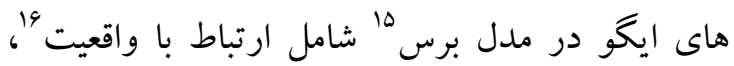

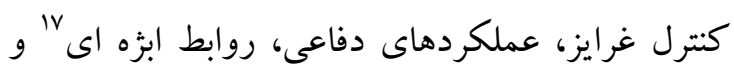

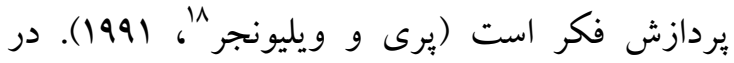

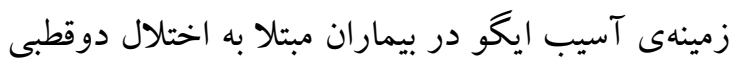
صرفاً يك بثوهش نشان داد كه آسيب ايخو در اين افراد بيشتر در حيطه ى ارتباط با واقعيت، يردازش فكر

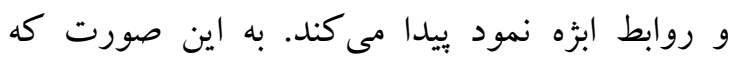

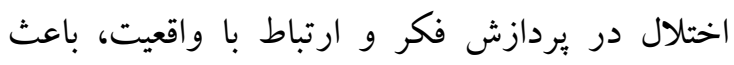
مهارت هاى اجتماعى و روابط بين فردى ضعيف و در نتيجه مانع حفظ روابط شىء مىشود (سيميسون،

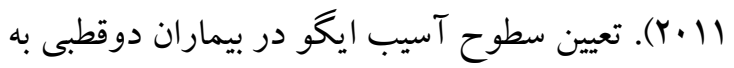
منظور روشن سازى موضوعات اصلى و تعارض ها كه براى روان درمانى لازم است، همجنين بيش بينى بيش

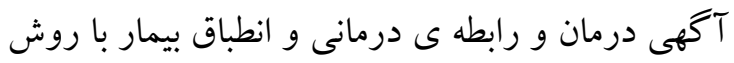

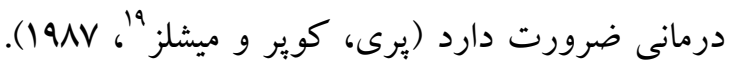
ييشينهى يزوهشى نشان مى دهد سنجش آسيب ايخو

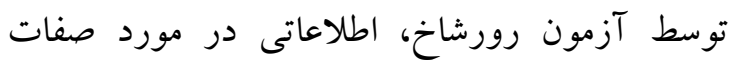

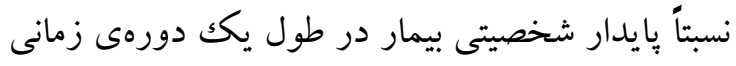

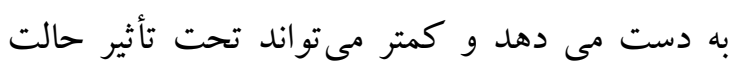

\footnotetext{
9 - Tsitsipa \& Fountoulakis

${ }^{10}$ - Psychosis

11 - Craddock \& Owen

12 - Simpson

13 - Ego Imperment

14 - Catherine

15 - Beres

16 - Reality testing

17 - Object Relatedness

${ }^{18}$ - Perry \& vilionejr

19. Perry, Cooper \& Michels
}

\footnotetext{
1 -Barry

${ }^{2}$-Miklovitz

3 - Mania

${ }^{4}$ - Hypomania

5 - Phillips \& Kupfer

6 - Diagnostic and statistical manual of mental disorders, Fifth Edition

7 - Calabrese, Hirschfeld, Reed, Davis, Frye, Keck

8 - Merikangas, Akiskal \& Angst
}

اختلال دوقطبى از نظر كلاسيك، تحت عنوان دوره

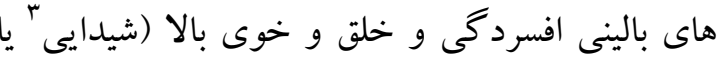
شيدايى خفيف +)، با دورههايى از خلق و خوى طبيعى

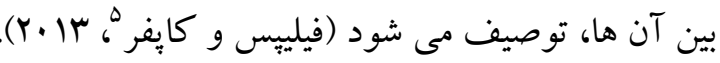
طبق بنجمين راهنماى تشخيصى و آمارى اختلالات روانى (DSM-5) دو نوع اختلال دوقطبى وجود دارد: اختلال دوقطبى نوع| و اختلال دوقطبى نوع II. براى تشخيص اختلال دوقطبى نوع ا حضور حداقل يك II دوره مانيك و براى تشخيص اختلال دو قطبى نوع حضور حداقل يكك دوره هييومانيك و حداقل يكك دوره افسردگى عمده لازم است (انجمن روانيزشكى آمريكا، سا.Y). اين اختلال در برخى نقاط دنيا، ناتوان كنندهترين اختلال شناخته شده است (كالابريس،

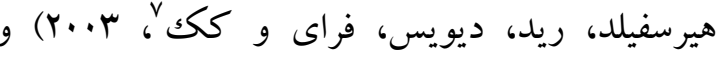
حدود F-1 درصد جمعيت را در بر گرفته و معمولا در سنين نوجوانى و اوايل بزرگكسالى بروز بيدا مى كند

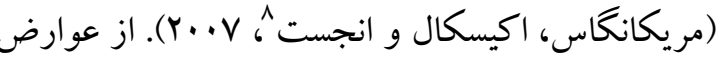
اين بيمارى مى توان به خلقوخوى بى ثبات، اختلال 
فردى، گروه درمانى، خانواده درمانى و زوج درمانى

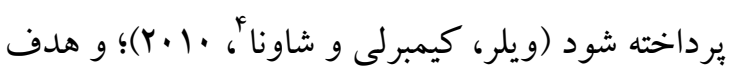
آن افزايش سطح آكاهى، يادگيرى تكنيك هاى

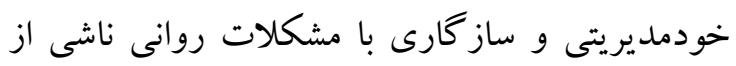
بيمارى با تأكيد بر نقاط قوت و مهارت دهارى بار ماز كارى

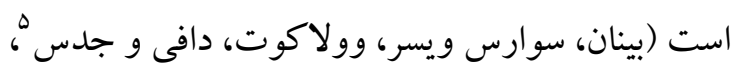

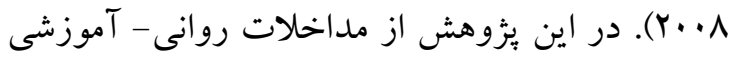
بارسلونا در مورد اختلال دو قطبى استفاده شد. اين روش مداخله به طور كلى به جهار حيطهى اصلى

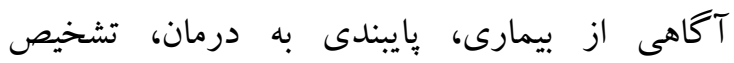

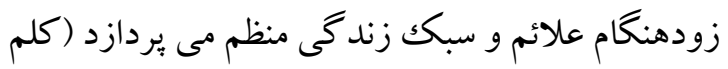

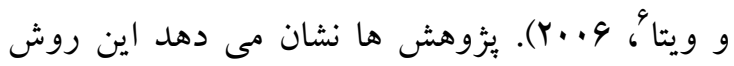
مداخله اي مستقل از تأثيرات دارويى، در كاهش علائم بيمارى دوقطبى مؤثر است. به طورى كه باعث عود

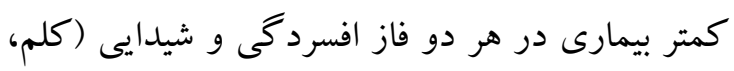

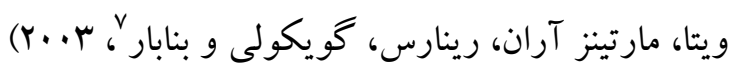
و در نتيجه كاهش روزهاى بسترى و تعداد دفعات بسترى در اين بيماران مى شود؛ كه اين نشاندهنده

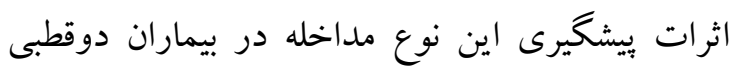

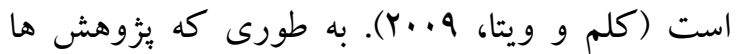
نشان مى دهد بيماران دوقطبى كه تحت درمان روانى آموزشى بارسلونا قرار گرفتند طى ب سال ييخيرى سطح ليتيوم كمترى نسبت به گروه همتا كه تحت تأثير اين بـ روش قرار نكرفته بودند، مصرف مى كردند (ميكلوويتز،

( $($... Y

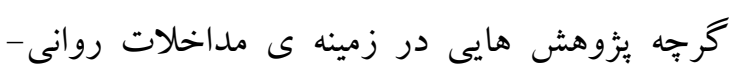
آموزشى بارسلونا بر روى اختلال دوقطبى انجام شده، با

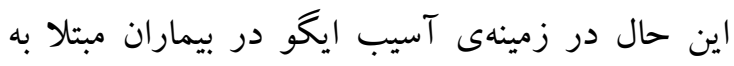

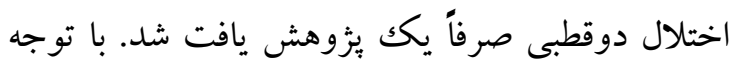

\footnotetext{
4- Wheeler, Kimberly \& Shawna

5 - Beynon, Soares-Weiser, Woolacott, Duffy \& Geddes

6 - Colom \& Vieta

7 - Colom, Vieta, Martinez-Aran, Reinares, Goikolea \& Benabarre
}

خاص بيمار در روز مصاحبه قرار داشته باشد (يرى،

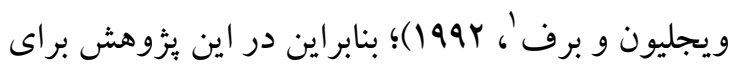
سنجش آسيب ايگو از آزمون رورشاخ استفاده شد. متغيرهاى نمايهى نقص ايخو در آزمون رورشاخ متناظر با روابط ابزهاى، بازنمايى هاى انسانى خوب (GHR) و

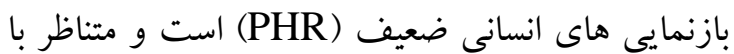
يردازش فكر، شاخصهاى ويزه (WSUM6) است (يرى و ويليونجر، 1991). GHR و PHR در آزمون رورشاخ نشاندهندهى نحوهى روابط بين فردى است. به طورى كه GHR نشان دهنده ى نحوه ى سازمان دهى كردن مناسب روابط بين فردى در موقعيت هاى مختلف است و PHR سازمان دهى ضعيف در اين زمينه را نشان مى دهد. WSUM6 نيز از جمع نمرات ويزه سطح يكك و دو در آزمون رورشاخ به دست مى نى

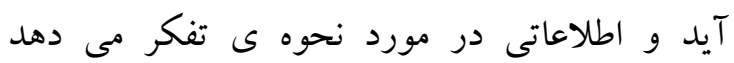

$$
\text { (اكسنر، ب... (Y) (1) }
$$

ييامدهاى اجتناب نايذير و ماهيت عود كننده اختلال دو قطبى سبب شده كه متخصصان به مراقبت و درمان اين اختلال توجه ويزه اى داشته باشند (ميكلوويتز، F ...... يثزوهش ها نشان مى دهد كه درمان دارويى به تنهايى براى بهبود كامل نشانها موفق نبوده است (باسيل،

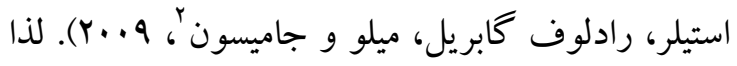
در سال هاى اخير به رواندرمانىها در كنار دارو درمانى توجه بيشترى شده است (ميكلوويتز، Y...F). يثزوهش ها نشان مى دهد كه مداخلات روانى تأثير

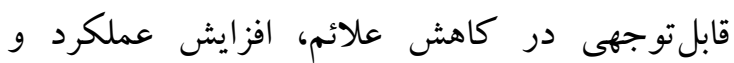
ساز گارى اجتماعى و كاهش عود بيمارى و تعداد

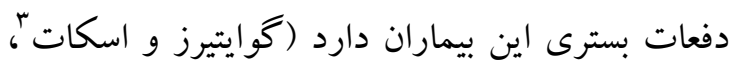

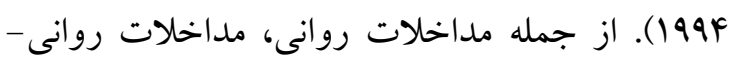

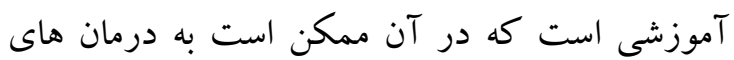

\footnotetext{
- Perry, Viglione\& Braff

2 - Bassil, Stiller, Radloff-Gabriel, Milev \& Jamieson

3. Guitierrez \& Scott
} 
9. اجراى بيش آزمون گروه آزمايشى در ال جلسه دقيقه اى تحت مداخله ى روانى - آموزشى بارسلونا

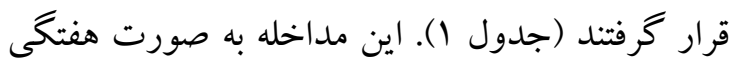
توسط يكى از يزوهشخران تعليم ديده در بخش

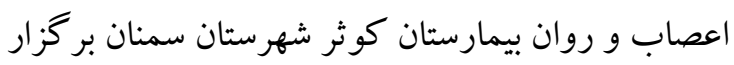

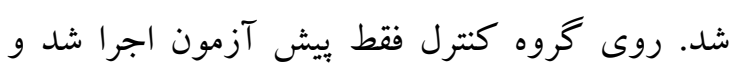
هيج گونه مداخله اى دريافت نكردند. يس از از اتمام

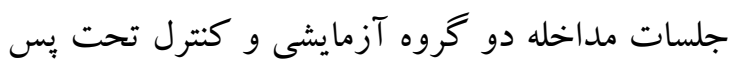
آزمون و همجينين سه بيگيرى به فو اصل زمانى دو ماهد

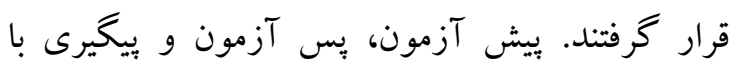

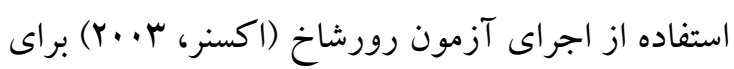

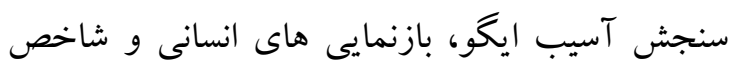
هاى ويزٔه در افراد نمونه، انجام شد. سبِ داده ها با استفاده از تحليل واريانس اندازه هاى مكرر در نرم افزار SPSS مورد تحليل قرار كرفتند. هدف تحليل بررسى تأثير مداخله روانى-آموزشى درم

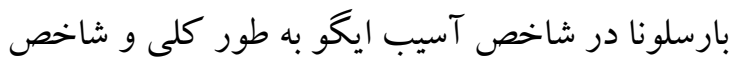
هاى بازنمايى هاى انسانى (متناظر با عملكرد روابط ابثر دئه

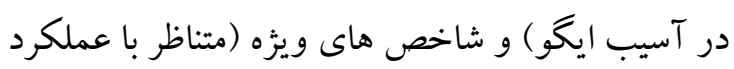
يردازش فكر در آسيب ايكو ) به طور جزئى است.
به عدم بثزوهش در مورد آسيب ايخو بر روى اختلال دوقطبى در ايران، همجنين عدم يافت يُزوهشى مبتنى بر بررسى تأثير مداخلات روانى-آموزشى بارسلونا بر آسيب ايخو در بيماران مبتلا به بيمارى دوقطبى، يثزوهش حاضر به منظور بررسى اثر مداخله روانى -

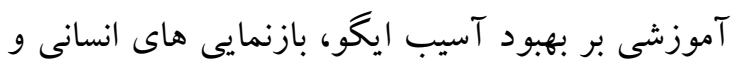

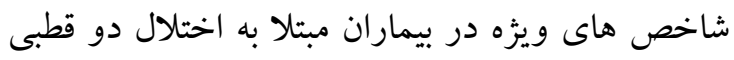
انجام شد.

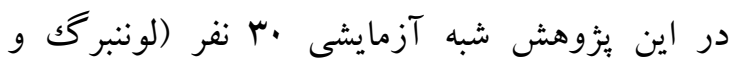

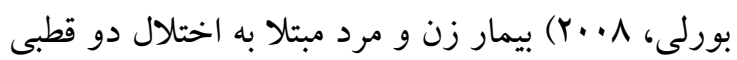
كه در سال هو و ماقبل آن در بخش اعصاب و روان بيمارستان كوثرشهرستان سمنان بسترى بودند، با استفاده

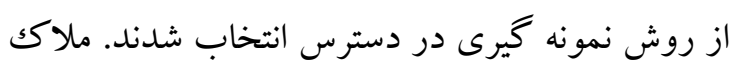
هاى ورود به نمونه شامل ابتلا به اختلال دو قطبى، عدم حضور همزمان در برنامه هاى مشابه مداخله روان

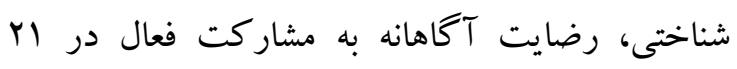
جلسه •و دقيقه ایى و ملاكك خروج از نمونه شامل اعتياد به مواد مخدر و الكل و همجِنين ابتلا به بيمارى روانى له

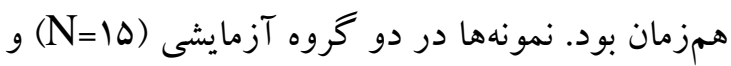

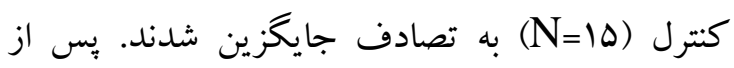

جدول ا محتواى جلسات روانى - آموزشى بارسلونا براى بيماران دو قطبى

\begin{tabular}{|c|c|}
\hline محتواى جلسات & جلسه \\
\hline مقدمه: ارائه قواعد گروه و اجراى بيش آزمون & جلسه اول \\
\hline آكاهى از اين كه اختلال دوقطبى جيست؟ & 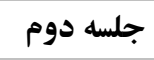 \\
\hline آكاهى از علل اختلال دوقطبى و ميزان شيوع آن در زن و مرد & 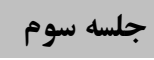 \\
\hline آكاهى در مورد علائم مانيا و هييومانيا & جلسه جهار \\
\hline آكاهى در مورد علائم افسردگى & جلسه هنج \\
\hline بحث در مورد تأثيرات و ييامدهاى اين اختلال و دورههاى باز گشت بيمارى، همجنين سوءمصرف & جلسه شش \\
\hline بحث در مورد داروهاى تثبيت كننده حلق، لزوم مصرف آن ها و عوارض جانبىشان & جلسه هفت \\
\hline بحث در مورد درمان دارويى و روان درمانى مانيا و هييومانيا & جلسه هشت \\
\hline بحث در مورد درمان دارويى و روان درمانى افسردگى & جلسه نه \\
\hline
\end{tabular}




\begin{tabular}{|c|c|}
\hline مصرف در درو مورد ميزان داروهاى تثبيت كننده خلق در خون و همجنين آزمايش هايى كه در دوران & جلسه ده \\
\hline بحث در مورد سؤالات مربوط به خطرات باردارى و عوارض مصرف داروها بر جنين & 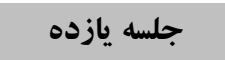 \\
\hline بحث در مورد درمان هاى غير علمى و عوارض آن ها & 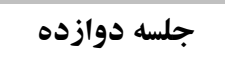 \\
\hline بحث در مورد خطرات مرتبط با قطع درمان دارويى & 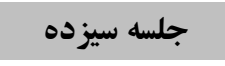 \\
\hline بحث در مورد عوارض خوددرمانى با مواد مخدر & جلسه جهارده \\
\hline بحث در مورد تشخيص زود هنگام علائم جنون & جلسه پيانزده \\
\hline بحث در مورد تشخيص زود هنگام علائم افسردگى و دوره هاى مختلط & 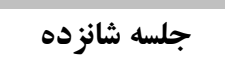 \\
\hline بحث در مورد آنجه بايد در فاز هييومانيا و فاز تركيبى و فاز مانيا انجام شود از جمله تنظيم عادات & 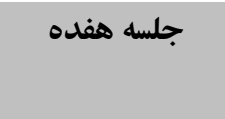 \\
\hline مطرح كردن نكاتى در مورد بعضى عادات زندگى از جمله خواب سالم & 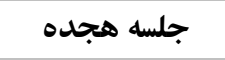 \\
\hline بحث در مورد روش هاى كنترل استرس & 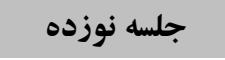 \\
\hline بحث در مورد راهبردهاى حل مسئله & 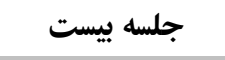 \\
\hline جمع بندى و ارائه كتاب هايى مفيد در مورد اختلال & جلسه بيست ويك \\
\hline
\end{tabular}

هاى حر كت انسانى با كيفيت منفى (M) و و متناظر با يردازش فكر، شاخص وزنى 9 نمره ويزه (Wsum6) نمره كذارى شدند.

\section{يافته ها}

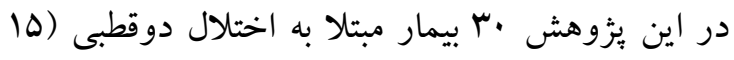

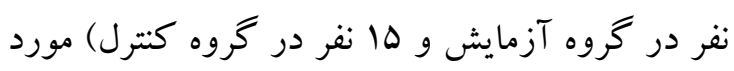

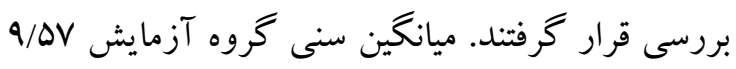
19/94 1 س

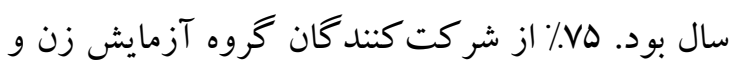

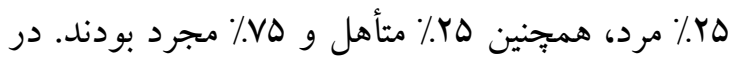

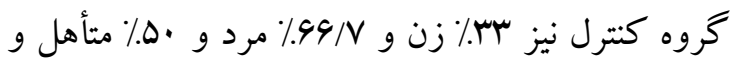

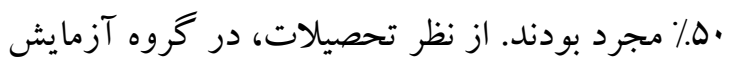

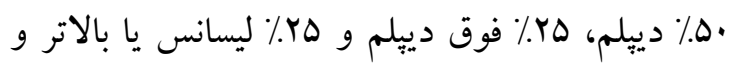

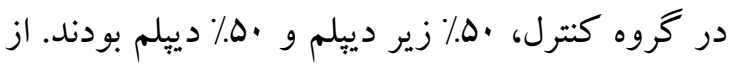
نظر وضعيت شغلى، در گروه آزمايش هr/\% بيكار، هبr\%

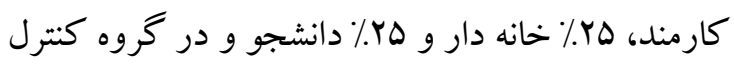

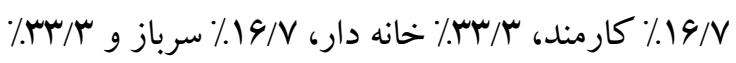
دانشجو بودند.
ابزار

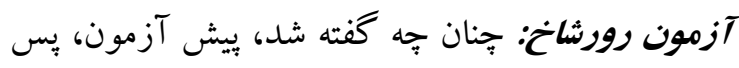
آزمون و ييگيرى با استفاده از اجراى آزمون رورشاخ

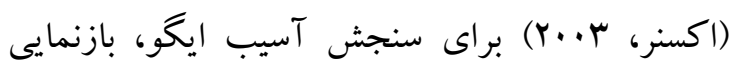
هاى انسانى و شاخص هاى ويزه در افراد نمونه، انجام شد. در اين ائزوهش اجرا و نمره گذارى آزمون رورشاخ بر اساس نظام جامع اسكنر صورت گرفت. بايايى اين

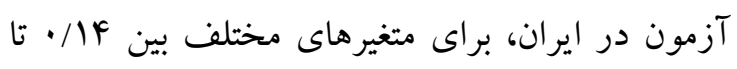

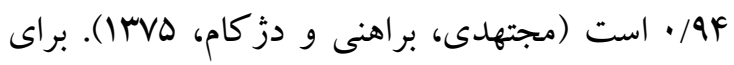
سنجش عملكرد ايخو طبق مدل برس (يرى و همكاران،

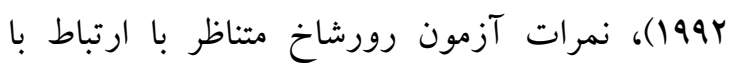
واقعيت، باسخ هاى فرافكن مجموع باسخ هاى با كيفيت

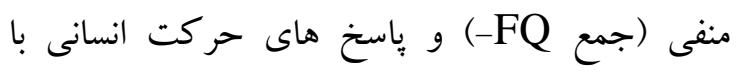
كيفيت منفى (M)-، متناظر با كنترل غرايز، باسخهاى

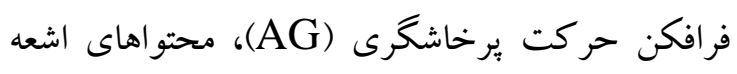

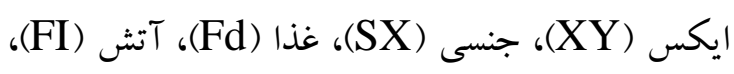

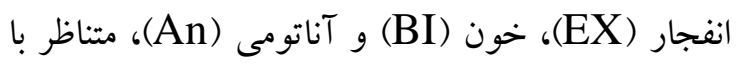
روابط ابزه، ياسخ هاى فرافكن بازنمايى انسانى خوب

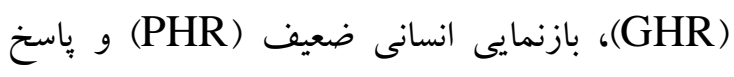




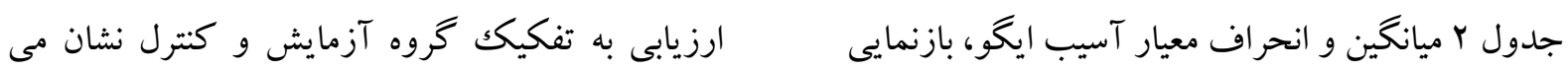
هاى انسانى و شاخص هاى ويزه را در ينج مرحله

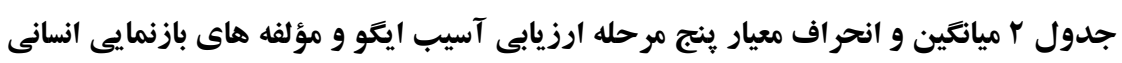

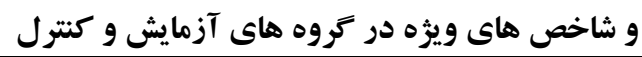

\begin{tabular}{|c|c|c|c|c|c|c|}
\hline يِيَيرى سوم & ييگيرى دوم & يِيَيرى اول & يس آزمون & يِي آزمون & & \\
\hline ميانگين \pm انحر اف & ميانگين 土 انحر اف & ميانخين 土 انحر اف & ميانخين 土 انحر اف & ميانگين \pm انحر اف & & \\
\hline معيار & معيار & معيار & معيار & معيار & & \\
\hline $1 \pm \cdot / \Lambda r$ & $r \pm \cdot / A r$ & $r / V \Delta \pm r / \Delta$ & $\Delta / r \Delta \pm r / .9$ & $1 \cdot / \Delta \cdot \pm r / v q$ & آزمايش & EII \\
\hline$\Lambda / \Lambda r \pm r / 19$ & $q / I V \pm r / V q$ & $N / \Delta \cdot \pm r / Q F$ & $\Lambda /|V \pm r / r|$ & $q / 1 V \pm r / 19$ & كنترل & \\
\hline$\Lambda \pm|/ F|$ & $\Delta / r \Delta \pm r / \Delta$. & $r / \Delta \pm r / \cdot \Lambda$ & $1 / V \Delta \pm \mid / V 1$ & $r \pm 1 / F 1$ & آزمايش & GHR \\
\hline $1 / \mu+1 / r$ & $1 / 9 V \pm 1 / r 1$ & $r \pm \cdot / 9 r$ & l/Ar $\pm 1 / F V$ & $1 / 9 V \pm 1 / 9 V$ & كنترل & \\
\hline$\cdot / r \Delta \pm \cdot / \Delta \cdot$ & $1 / \Delta \cdot \pm \cdot / \Delta \Lambda$ & $r / \Delta \cdot \pm 1$ & $r / \Delta \cdot \pm 1 / r q$ & $9 \pm 1 / 94$ & آزمايش & PHR \\
\hline$\Delta / I V \pm Y / r Y$ & $F / q V \pm 1 / T V$ & $\Delta / I V \pm Y / \cdot F$ & $\Delta /|V \pm Y / V|$ & $\Delta / A r \pm Y / Y r$ & كنترل & \\
\hline$\cdot / r \Delta \pm \cdot / \Delta$. & $r \pm \cdot / \Lambda r$ & $1 / V \Delta \pm \cdot / 9 \varphi$ & $r / \Delta \cdot \pm \cdot / \Delta \Lambda$ & $1 \Delta / Y \Delta \pm V / \Delta q$ & آزمايش & WSUM6 \\
\hline $\mid F \pm q / A F$ & $\mid F / \Delta \cdot \pm N / I V$ & $\mid r / \Delta \cdot \pm V / r q$ & $\mid F / M r \pm 9 / 91$ & $\mid F / I V \pm V / \Delta V$ & كنترل & \\
\hline
\end{tabular}

براى تجزيه و تحليل داده ها آزمون تحليل واريانس بين آزمودنى ها و درون آزمودنى ها با اندازه كيرى لهاى

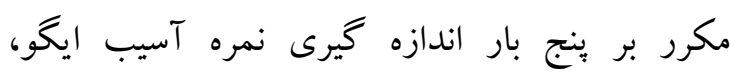

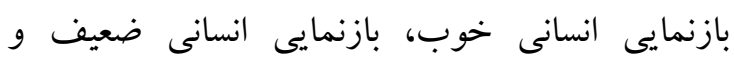
نمرات ويزه در گروهه هاى درمانى و كنترل انجام شد. بارئ. نتايج در جدول شماره ى ب ارائه شده است.
قبل از اجراى آزمون تحليل واريانس اندازه هاى مكرر، بيش فرض هاى آن بررسى شد. با بررسى آزمون لوين،

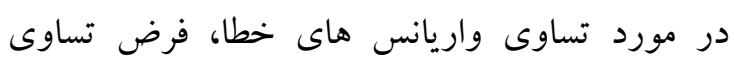
واريانس ها رعايت شد و واريانس خطاى متغيرهاى هوردي وابسته در تمام گروه ها مساوى بود.

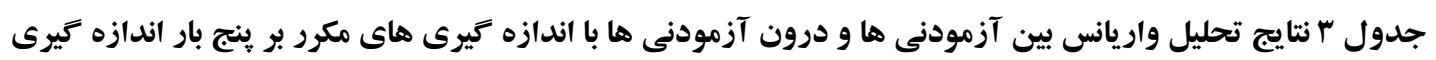

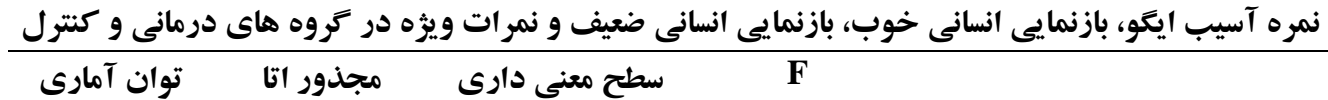

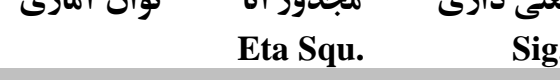

\begin{tabular}{|c|c|c|c|c|}
\hline 1 & $\cdot / 19$ & $\%$ & $9 \pi / 49$ & تأثير بين كروهى EII \\
\hline$\cdot 109$ & . $/ F Y$ &.$/ .4$ & $\Delta / v \wedge$ & تعامل EII و كروه \\
\hline ./99 & .194 &.$/ .1$ & $1 r / 94$ & تأثير درون كروهى EII \\
\hline 1 & $\cdot / \wedge 9$ & 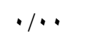 & $9 \% / .0$ & تأثير بين تروهى GHR \\
\hline$\cdot / \wedge \Delta$ & $\cdot / \Delta 9$ &.$/ \cdot 1$ & $11 / 90$ & تعامل GHR و كروه \\
\hline.$/ 99$ & .194 & $\%$ & $1 \mathrm{r} / \mathrm{WV}$ & تأثير درون كروهى GHR \\
\hline 1 & $\cdot / \wedge q$ & $\%$ & $94 / 94$ & تأثير بين كروهىPHR \\
\hline$\cdot / \Delta \Lambda$ &.$/ 4 r$ &.$/ . F$ & 91.4 & تعامل PHR و كروه \\
\hline$\cdot / A V$ & $\cdot / 4 \Delta$ & $\bullet \cdot \cdot v$ & $9 / 09$ & تأثير درون كروهى PHR \\
\hline
\end{tabular}




\begin{tabular}{|c|c|c|c|c|}
\hline$\cdot / 99$ & - /V9 & $\cdot / \cdots 1$ & $r \Delta / 1 \Delta$ & تأثير بين كروهى WSUM6 \\
\hline$\cdot / 09$ & $\cdot / F F$ & $\cdot / \cdot F$ & $9 / 19$ & تعامل WSUM6 و Fروه \\
\hline 1 & $.19 \mathrm{~V}$ & $\cdot 1$ & $19 / 9 \pi$ & تأثير درون تروهى WSUM6 \\
\hline
\end{tabular}

درمانى و كترل ارائه شده است. لازم به ذكر است براى

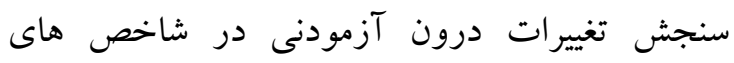
آسيب ايكو و بازنمايى انسانى ضعيف، از اثر همر خطى درنى و در شاخص بازنمايى انسانى خوب و نمرات ويزٔه از

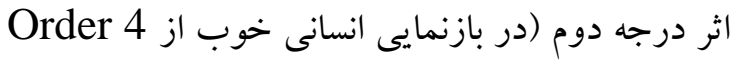

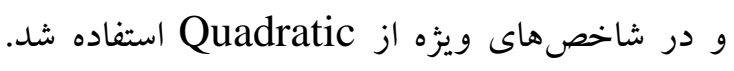

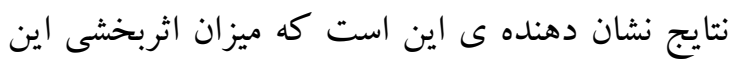

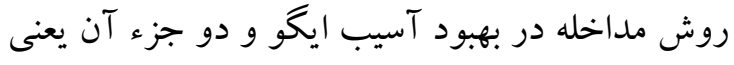
روابط ابزٔه و يردازش فكر در طول زمان ثابت است. به ديه عبارتى عامل زمان در كاهش ميزان اثربخشى اثر نداشته است. توان آمارى نيز حاكى از دقت معنادارى در اين

$$
\text { روابط على هستند. }
$$

نمودار ا تفاوت ميانگين آسيب ايكو، بازنمايى انسانى خوب، بازنمايى انسانى ضعيف و نمرات ويزه را طى آلى آنى آنساني مر احل ييش آزمون و يس آزمون نشان مى دهد.

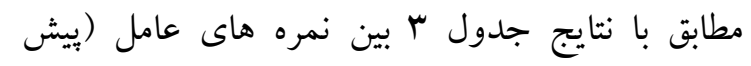

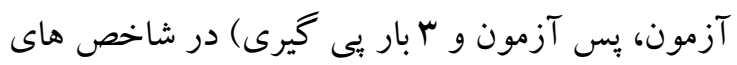

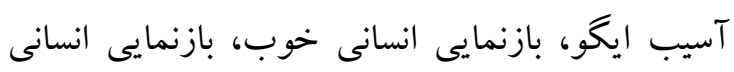

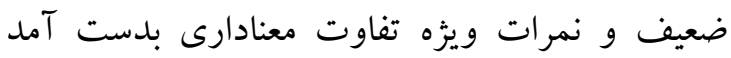

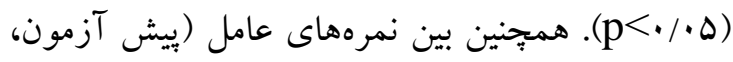

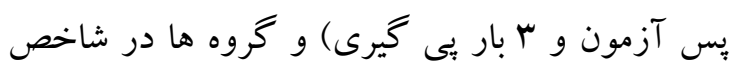

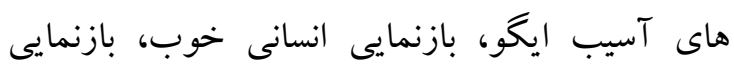
انسانى ضعيف و نمرات ويزٔه تعامل معنادارى مشاهده

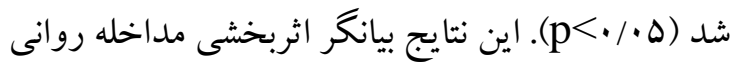

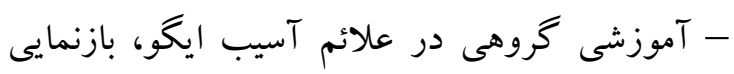

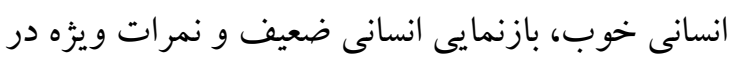
بيماران مبتلا به اختلال دوقطبى است. همجنين در اين جدول نتايج تحليل واريانس درون

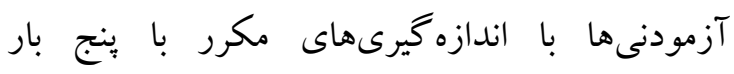

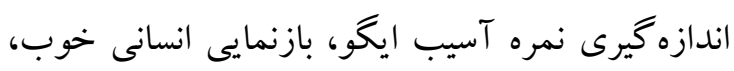

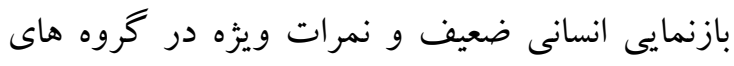

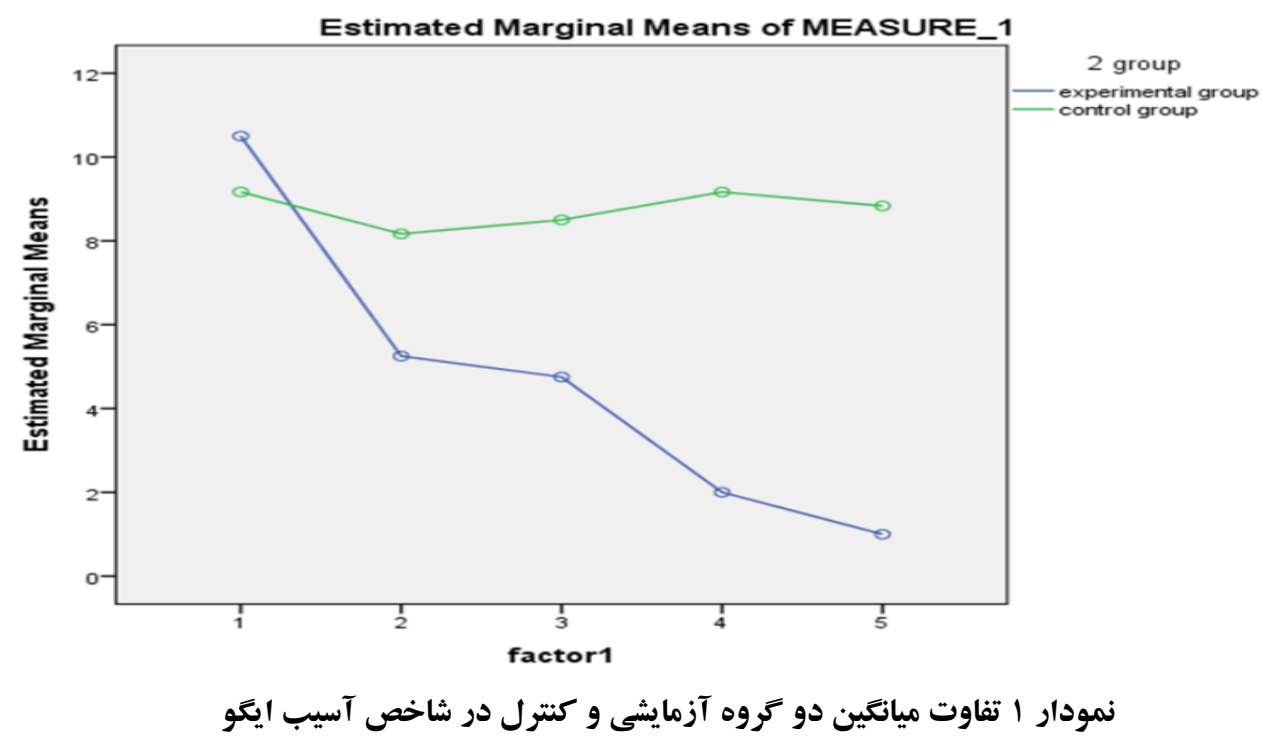



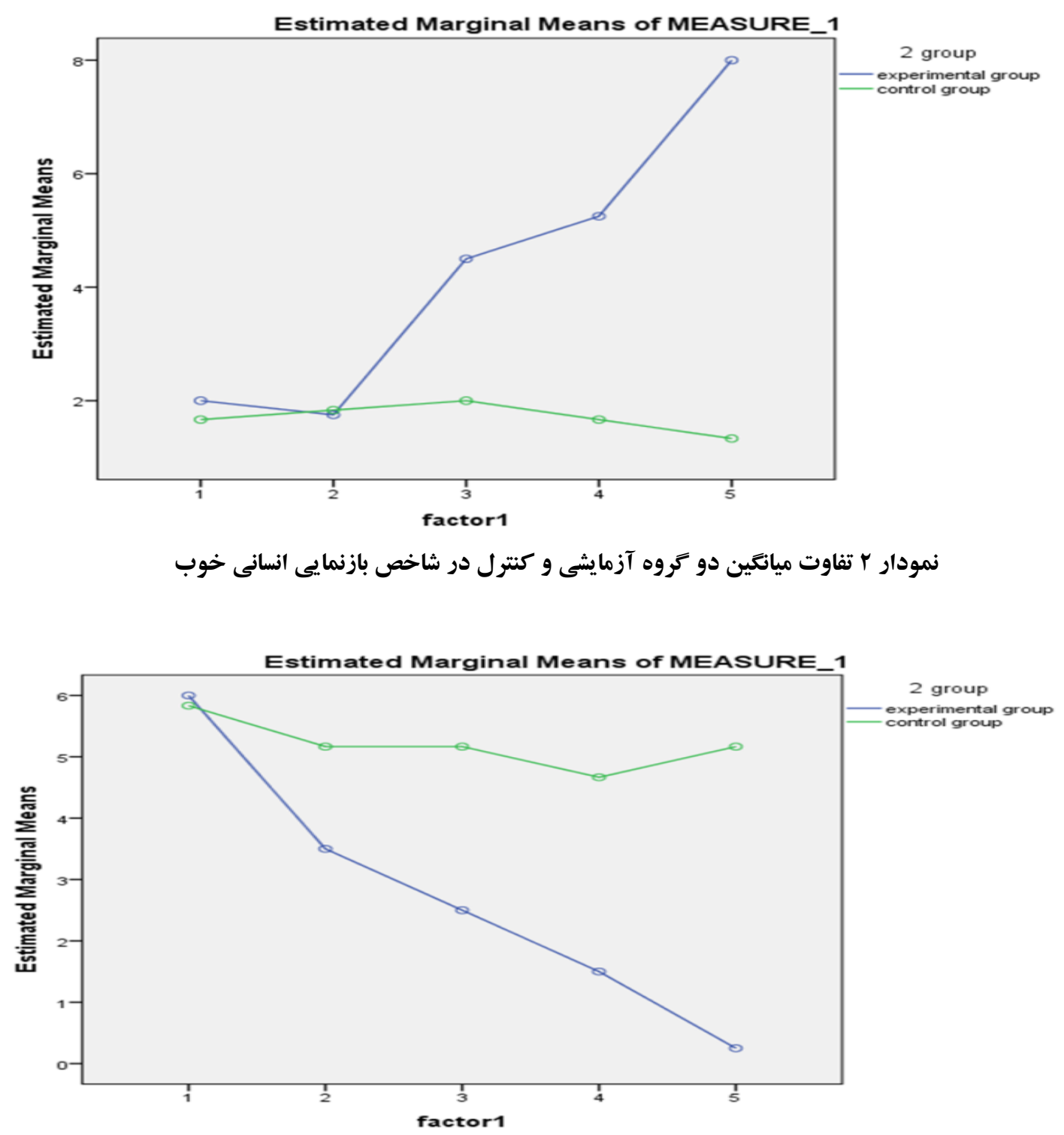

نمودار r تفاوت ميانكين دو كروه آزمايشى و كنترل در شاخص بازنمايى انسانى ضعيف

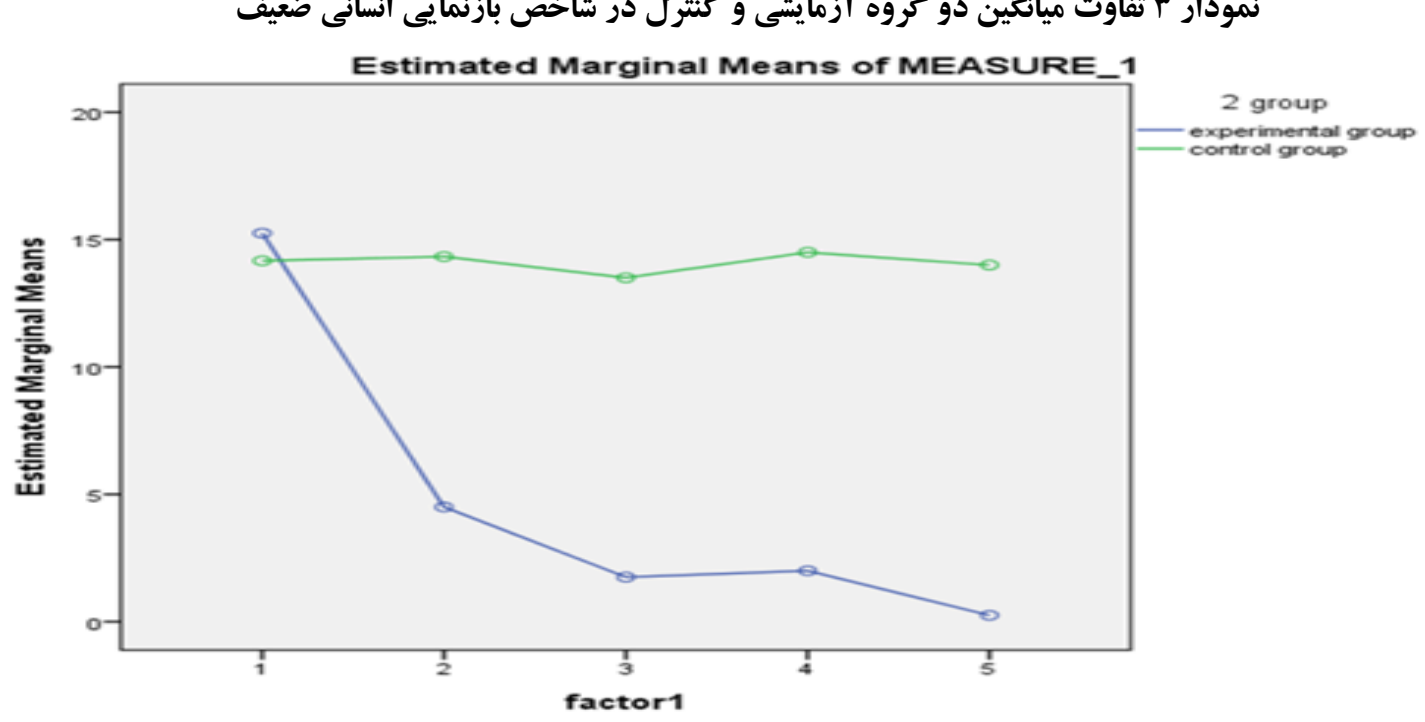

نمودار f تفاوت ميانكين دو كروه آزمايشى و كنترل در شاخص نمرات ويزه 


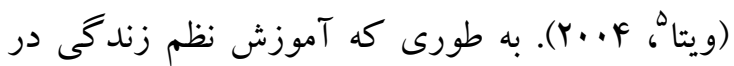

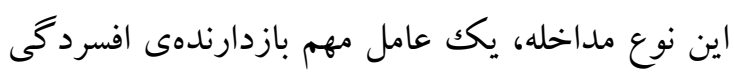
است. همجِين تشخيص زودهنكام علائم بيش در آمد،

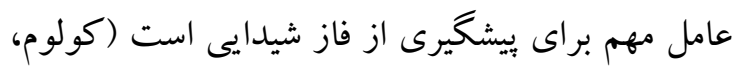

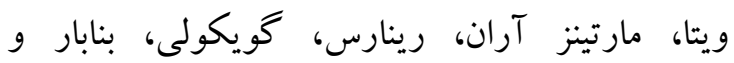

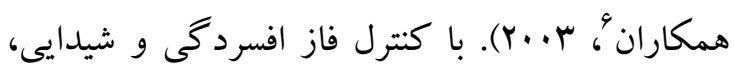
همجِين آكاهى بيمار در مورد اين بيمارى، سيستم يردازش فكر بيمار در سطح مطلوب ترى قرار مى گيرد؛

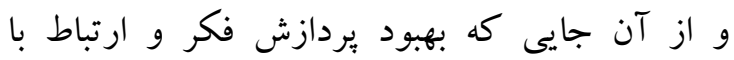
واقعيت، مهارت هاى اجتماعى و روابط بين فردى و در نتيجه روابط شى ء را بهبود مى بخشد (سيميسون، T) آموزشى بارسلونا باعث بهبود آسيب ايگو در بيماران دوقطبى مى شود. از محدوديت هاى اين بيزوهش مى توان به به عدم امكان

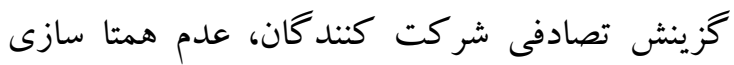
بيماران از نظر ميزان آسيب ايگو و عدم كنترل متغيرهاى مداخله كر از جمله فرهنگك و متغيرهاى جمعيت شناختى نام برد. همجِنين از مشكلات اين يثزوهش مى توان به انگيزه كم اوليه لى بيماران به دليل

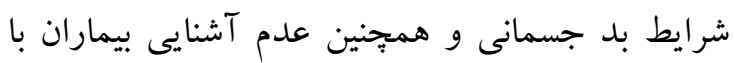

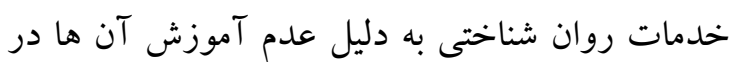
بيمارستان ها در كنار آموزش هاى بز شكى اشهاره كرد. ييشنهاد مى شود در مطالعات بعدى دو گروه آزمايشى و

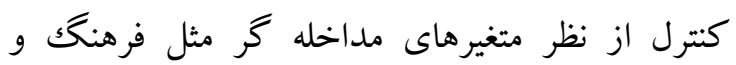

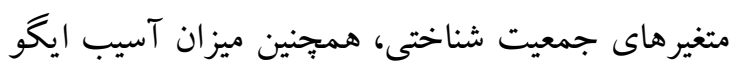
همتا شوند. هميجنين بيشنهاد مى شود براى آزمودنى

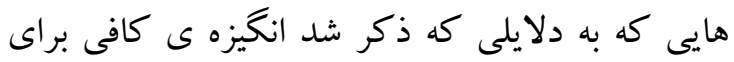
شركت در جلسات ندارند مصاحبه ى انكيزشى انجام

\footnotetext{
5 -Vieta

${ }^{6}$ - Colom, Vieta, Martinez-Aran, Reinares, Goikolea, Benabarre $\&$ etal
}

ي يشينه يُزوهشى نشان دهنده ى آسيب ايخو در بعضى از بيماران دوقطبى است. آسيب ايخو در اين افراد بيشتر در حيطه ى ارتباط با واقعيت، بردازش فكر و روابط

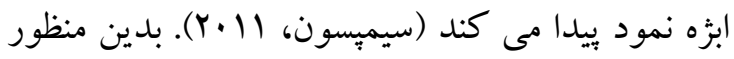

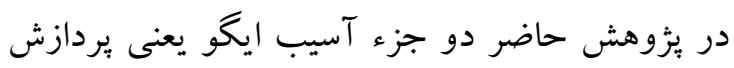

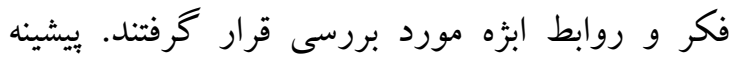

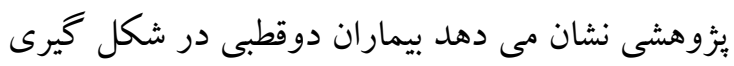
و حفظ روابط صميمانه، همجِين ابراز صميميت ضعف

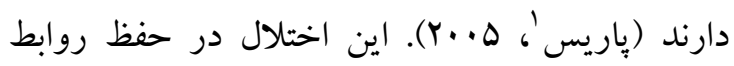
صميمانه را مى توان به عدم روابط شىء بـ باثبات درونى آنى

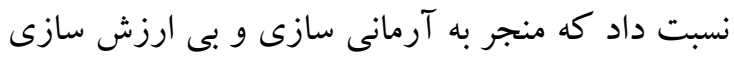
ديخران، ترس از رهاشدگى و حساسيت نسبت به طرد و در نتيجه مشكلات فراگير در روابط بين فردى در اين

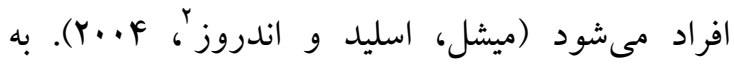
عبارتى كاهش ظرفيت روان- شناختى روابط شى در اين بيماران، عامل مهم در كاهش تعاملات اجتماعى

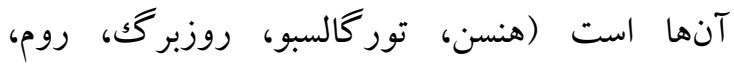

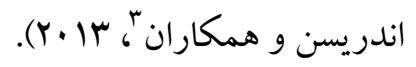

همجِنين يُروهش هاى قبلى نشان مى دهند كه مداخلات روانى-آموزشى بيماران دوقطبى در بهبود اين بيمارى و كاهش عود آن مؤثر است (جوستو،

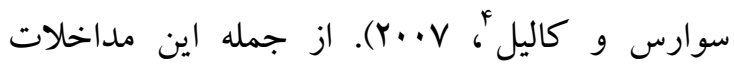

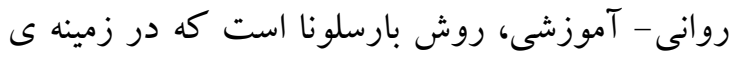
اطلاعات در مورد اختلال، درمان، آموزش حل مسئله، بهبود مهارت هاى ارتباطى و كنترل استرس است (راهنماى مداخلات روانى اجتماعى در اختلالات

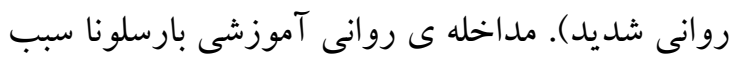
تثبيت خلق در دوره هاى حاد مانيا و افسردگى مى شود

\footnotetext{
1 -Paris

2 - Mitchell, Slade \& Andrews

3 - Hansen, Torgalsbo, Rossberg, Romm \& Andreassen,

4 - Justo, Soares \& Calil
} 
Colom F, Vieta E, Martinez-Aran A, Reinares M, Goikolea JM, Benabarre A, et al. (2003). A randomized trial on the efficacy of group Psychoeducation in the prophylaxis of recurrences in bipolar patients whose disease is in remission. Archives of General Psychiatry, 60, 402-407.

Colom F, Vieta E. (2006). Psychoeducation Manual for Bipolar Disorder. Cambridge University Press.

Colom F, Vieta E. (2009). Psychoeducation for bipolar disorders, In: Kaplan \&Sadock's Comprehensive Textbook of Psychiatry. 9th Edition. New York: Lippincott Williams \& Wilkins.

Craddock N, Owen MJ. (2010). The Kraepelinian dichotomy going, going... but still not gone. Br. J. Psychiatry, 196, 92-95.

Exner JE. (2003). The Rorschach: A Comprehensive System. 4th ed. United State: John Wiley \& Sons Inc.

Guitierrez M, Scott J. (1994). Psychological treatment for Bipolar Disorders. European Archives of Psychiatry and Clinical Neuroscience, 254(2), 92-98.

Hansen CF, Torgalsbo AK, Rossberg JI, Romm KA, Andreassen OA, Bell MD, Melle I. (2013). Object Relations, Reality Testing, and Social Withdrawal in Schizophrenia and Bipolar Disorder. Joumal of Nervous and Mental Disease, 201(3).

Justo LP, Soares BG, Calil HM. (2007). Family interventions for bipolar disorder. Cochrane Database Syst Rev,167(4).

Lunenburg FC, Beverly JI. (2008). Writing a successful thesis or Dissertation: Tips and strategies for students in the Social and Behavioral Sciences. Netherland: Corwin Pres Inc.

Merikangas K R, Akiskal HS, Angst J. (2007). Lifetime and 12 month prevalence of bipolar spectrum disorder in the National Comorbidity Survey replication. Arch. Gen Psychiatry, 64, 543-552.

Miklovitz DJ. (2004). Family-focused treatment foradolescence with bipolar disorder. Joumal of Affective Disorders, 82,113-128.

Mitchell PB, Slade T, Andrews G. (2004). Twelvemonth prevalence and disability of DSM-IV bipolar disorder in an Australian general

$$
\begin{aligned}
& \text { شود و در صورت لزوم اين آزمودنى ها از شركت در } \\
& \text { ئزوهش حذف شوند. } \\
& \text { نتيجه كيرى }
\end{aligned}
$$

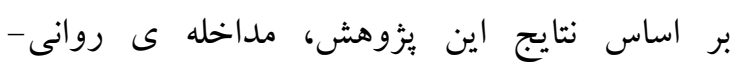

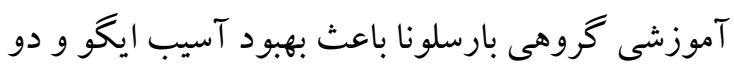

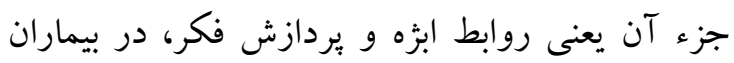

$$
\begin{aligned}
& \text { مبتلا به اختلال دوقطبى مى شود. } \\
& \text { سياستز ارى } \\
& \text { از همكارى بيرسنل بيمارستان كوثر شهرستان سمنان كه } \\
& \text { در انجام اين بثزوهش ما را يارى نمودند نهايت تشكر و }
\end{aligned}
$$

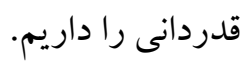

\section{References}

American Psychiatric Association. Diagnostic and statistical manual of mental disorders.(2013). 5th edtext version. Washington DC: Author.

Barry PD. (2001). Mental health and mental illness. 7th ed. NewYork: Lippincott Williams \& Wilkins.

Bassil R, Stiller A, Radloff-Gabriel D, Milev R, Jamieson M. (2009). Pilot evaluation of a psychoeducational group for people with bipolar disorder. Queen's Health Sciences Joumal, 9(2), 12-16.

Beynon S, Soares-Weiser K, Woolacott N, Duffy S, Geddes JR. (2008). Psychosocial interventions for the prevention of relapse in bipolar disorder: systematic review of controlled trials. British Journal of Psychiatry, 192, 5-11.

Calabrese JR, Hirschfeld RM, Reed M, Davis M, Frye M, Keck P, et al. (2003). Impact of bipolar disorder on a US community sample. Journal of Clinical Psychiatry, 64, 425-432.

Catherine HM. (2009). Examining the impact of the Ego Impaiment Index (EII-2) and psychopathology on childhood psychiatric symptoms: Interactions with developmental indicators: PACEUNIVERSITY. 
population survey. Psychological Medicine, 34, 777-785.

Mojtahedi M, Baraheni MN, Dezhkam M. [Preliminary standardization of Rorschach test based on Exner comprehensive system]. MA. Dissertation. Tehran: Institute of Psychiatry University, College of psychology and education science, 1996: 71-91.(Persian)

Paris J. (2005). Borderline personality disorder. Canadian Medical Association Journal, 172(12), 1579-1583.

Perry S, Cooper A, Michels R. (1987). The Psychodynamic Formulation: Its Purpose, Structure and Clinical Application American. Journal of Psychiatry, 144, 543550.

Perry W, Viglione DJ, Braff D. (1992). The Ego Impairment Index and schizophrenia: A validation study. Joumal of Personality Assessment, 59, 165-175.

Perry w, vilionejr DJ. (1991). the Ego impairment index as a predictor of outcome in melancholic depressed patrents treated with tricyclic antidepressant. jounnal of personality assessment, 56(3), 487-501.

Phillips ML, Kupfer DJ. (2013). Bipolar disorder diagnosis: challenges and future directions. Lancet, 381, 1663-1671.

Simpson JL. (2011). An exploration of ego impairment in Bipolar Mood Disorder using the Ego Impairment Index-2 [dissertation]. MA Clinical Psychology: University of Pretoria.

Tsitsipa E, Fountoulakis K. (2015). The neurocognitive functioning in bipolar disorder: a systematic review of data. Ann Gen Psychiatry, 14, 42.

Vieta E. (2004).Maintenance therapy for bipolar disorder: current and future management options. Expert Rev Neurotherapeutics, 4(2), 35-42.

Wheeler LA, Kimberly AU, Shawna MT. (2010). Conflict Resolution in Mexican-origin Couples: Culture, Gender, and Marital Quality. Journal Marriage Fam, 72(4), 9911005. 